\title{
PRÁTICAS DE LINGUAGEM E SABERES LOCAIS EM CONTEXTO DE FRONTEIRAS
}

\section{Language Practices and Local Knowledge in Context of Boundaries}

DOI: $10.14393 /$ LL63-V35nEsp2019-17

\author{
Maria Elena Pires-Santos* \\ Regina Coeli Machado e Silva**
}

\begin{abstract}
RESUMO: Este artigo tem como objetivo apresentar uma experiência de participação colaborativa professores de um colégio estadual, alunos e outros atores da comunidade escolar, incluindo moradores do bairro onde está situado o colégio, professores da Universidade e acadêmicas dos cursos de Letras que possibilitou a emergência de saberes locais e práticas de linguagem, por meio do desenvolvimento de um projeto, intitulado "Projeto Memória". Teve como finalidade reconstruir a história de formação do Bairro e do colégio, contou com professores de diferentes áreas do conhecimento e permitiu que todos, percebessem as inter-relações constitutivas entre o contexto escolar e os modos de existência local. A experiência etnográfica construída com o Projeto evidenciou a importância do trabalho coletivo, o qual teve como pressupostos uma pedagogia inspirada em uma perspectiva culturalmente sensível e se estendeu para além das paredes da sala de aula e dos muros do colégio.
\end{abstract}

PALAVRAS-CHAVE: Práticas de linguagem. Saberes locais. Fronteiras. Etnografia. Trabalho colaborativo.

ABSTRACT: This article aims to present an experience of collaborative participation - teachers from a state college, students and other actors from the school community, including residents of the neighborhood where the college is located, university teachers and scholars of Letters courses - which made possible the emergence of local knowledge and language practices through the development of a project entitled "Memory Project". Its purpose was to reconstruct the history of the formation of the neighborhood and the school, counted on teachers from different areas of knowledge and allowed everyone to understand the constitutive inter-relationships between the school context and the local ways of existence. The ethnographic experience built on the Project has highlighted the importance of collective work, which was based on a pedagogy inspired by a culturally sensitive perspective and extended beyond the walls of the classroom and the walls of the school.

KEYWORDS: Linguistic practices. Local knowledge. Borders. Ethnography. Collaborative work.

\footnotetext{
* Doutora em Linguística Aplicada, professora Sênior do Mestrado/Doutorado em Letras, Mestrado/Doutorado em Sociedade, Cultura e Fronteiras e Profletras - Unioeste/Paraná. ORCID: 0000-0002-1979-2090. E-mail: mepires(AT)gmail.com.

** Doutora em Antropologia Social, professora Sênior do Mestrado/Doutorado em Letras, Mestrado/Doutorado em Sociedade, Cultura e Fronteiras, Unioeste/Paraná, professora Visitante na UNILA e pesquisadora Produtividade do CNPq. ORCID: 0000-0002-0874-8086. E-mail: coeli.machado(AT)yahoo.com.br
} 


\section{Introdução}

O objetivo deste artigo é apresentar uma experiência de participação colaborativa professores de um colégio estadual, alunos e outros atores da comunidade escolar, incluindo moradores do bairro onde está situado o colégio, professores da Universidade e acadêmicas dos cursos de Letras - que possibilitou a emergência de saberes locais e práticas de linguagem, por meio do desenvolvimento de um projeto, intitulado "Projeto Memória". O projeto foi proposto e implementado por professores, alunos, pais de alunos e moradores do Bairro.

O bairro é relativamente novo e foi resultante das negociações entre o poder público local e moradores, quando foram retirados de uma ocupação às margens do rio Paraná, na região central da cidade. O "Projeto Memória", desenvolvido de 2010 a 2013, foi um dos resultados de um de um projeto mais amplo ${ }^{1}$, desenvolvido por professores e alunos da graduação e da pós-graduação da Universidade, em Foz do Iguaçu.

Pelo fato de a cidade estar situada em uma região fronteiriça com países hispânicos Paraguai e Argentina - apresenta uma situação linguística, cultural e social extremamente complexa e desafiadora, parte também do contexto escolar. Trata-se de uma região colonizada inicialmente por italianos e alemães - que muitas vezes ainda mantêm suas línguas de origem - e por receber imigrantes de vários países (árabes, chineses, coreanos, etc.), atraídos pela região de livre comércio de Ciudad del Este, e das mais diferentes regiões do Brasil. Além das características econômicas, turísticas, fronteiriças daí resultantes, a construção da Usina de Itaipu atraiu pessoas de outros países e diversas regiões brasileiras. Pelas suas configurações, pode ser caracterizada como região de 'superdiversidade', conforme propõe Vertovec (2007) e também Blommaert e Rampton (2011). Vertovec (2007), com a finalidade de abordar a "diversificação da diversidade" na Grã-Bretanha e buscando sublinhar um nível e tipo de complexidade que, segundo o autor, supera qualquer situação que se tenha experimentado

\footnotetext{
${ }^{1}$ Inserido nas linhas de pesquisa "Linguagem: Práticas Linguísticas, Culturais e Ensino" e "Estudos da Linguagem: descrição dos fenômenos linguísticos, culturais, discursivos e de diversidade", do mestrado/doutorado em Letras da Unioeste/PR, bem como na linha de pesquisa Lnguagem, Cultura e Identidade do mestrado/doutorado Interdisciplinar em Sociedade, Cultura e Fronteiras, os resultados apresentados são parte do projeto interdisciplinar "Observatório de Educação: Núcleo de Pesquisa e Extensão em leitura, escrita e oralidade", financiado pela CAPES/INEP, a quem agradecemos, e também vinculado ao Procad (PROCAD/CAPES/06/2011-1Casadinho/CNPq/CAPES/processo/552450/2011-1). Os coordenadores do projeto são docentes e pesquisadores dos dois Programas.
} 
anteriormente, assinala que essa expressão foi cunhada para compreender o cenário de grande mobilidade de pessoas ao redor do mundo, que vem ocorrendo na atualidade.

Enfocar o contexto escolar nesse cenário de superdiversidade e, particularmente, no modo de existência na fronteira, foi nossa preocupação inicial, quando nos inserimos no Observatório de Educação, um Programa de abrangência nacional, proposto inicialmente em 2006 pela Coordenação de Aperfeiçoamento de Pessoal de Nível Superior (Capes), juntamente com o Instituto Nacional de Estudos e Pesquisas Educacionais Anísio Teixeira (INEP), ambos vinculados ao Ministério da Educação (MEC). Este Programa, agora extinto pelo MEC, estava inserido nas políticas e metas estabelecidas no Plano de Desenvolvimento da Educação (PDE) que procurava, justamente, a elevação do Índice de Desenvolvimento da Educação Básica (IDEB), cuja meta era alcançar, até 2022, o índice de 6,0, numa escala de 0 a 10. A média nacional registrada em 2007 foi de 4,2 para a 4a série e 3,8 para a 8a série e 3,5 para o Ensino Médio $^{2}$. O IDEB da escola em que foi desenvolvido o projeto apresentava o índice de 3,4, conforme dados do INEP, de 2009. Com base nesses dados, entendia-se de forma clara a intencionalidade da gestão de políticas voltadas para a busca de resultados, auferidos por sistemas de avaliações universalizantes. Mas, foi justamente essa percepção que impulsionou a busca de possibilidades que nos propiciassem, diante dessa inequívoca intencionalidade, não apresentar um projeto pronto para a transmissão de saberes constituídos para serem aplicados na escola. Pelo contrário, decidimos que todas as atividades fossem pensadas e realizadas conjuntamente, para que houvesse não só espaço para o fortalecimento dos laços e da aprendizagem recíproca entre professores universitários, alunos da graduação, professores da educação básica, alunos da educação básica, gestores e moradores mas, principalmente, para que estivéssemos abertos aos modos de existência locais.

O Projeto foi realizado entre os dois Programas de Pós-Graduação da Unioeste Mestrado/Doutorado em Letras, campus de Cascavel e Mestrado/Doutorado em Sociedade, Cultura e Fronteiras, campus de Foz do Iguaçu - o Colegiado dos Cursos de Letras/Português/Inglês/Espanhol, o Núcleo Regional de Educação (NRE) e o Colégio Estadual. Todas as atividades tiveram como finalidade favorecer a cooperação entre os diferentes níveis

\footnotetext{
${ }^{2}$ Conforme consta no Edital No. 038/2010/CAPES/INEP.
} 
educacionais - Pós-Graduação Strictu Sensu, Graduação, Ensino fundamental e Médio e os moradores do bairro - com a motivação de, incluindo os saberes locais, contribuir para a melhoria dos níveis educacionais. Também estavam presentes professores de várias áreas do conhecimento que atuavam no colégio (português, matemática, geografia, ciências, artes, inglês) os quais, primordialmente, são professores de leitura, escrita e oralidade, propiciando a interdisciplinaridade. A abrangência das atividades aí propostas proporcionou, de modo inesperado, estabelecer vínculos mais próximos e formas de participação dos moradores do Bairro, como queremos mostrar.

Com esses diferentes participantes, as atividades foram propostas e construídas conjuntamente, centrando-se na formação recíproca em todos os níveis (professores, futuros professores, alunos e formadores de professores, pedagogos, alunos do ensino fundamental e médio, funcionários da escola e moradores do bairro), o que demonstrou a importância da construção de ações coletivas e interdisciplinares em processos de aprendizagens ampliadas, que extrapolam preocupações apenas conteudistas escolarizadas, estendendo-se para além dos muros da escola e, ao mesmo tempo, incluindo os saberes locais. Para tanto, procuramos uma aproximação entre o desenvolvimento de pesquisas acadêmicas e as práticas dos professores da educação básica, evidenciando que é possível, a partir de trabalhos conjuntos, rumar em direção a uma educação diferenciada e eficiente, a fim de vencer os desafios para uma educação "culturalmente sensível” (ERICKSON, 1987; LADSON-BILLINGS, 1994; BORTONIRICARDO; DETTONI, 2003), principalmente quando se tratam de alunos que pertencem a grupos populares menos favorecidos, como evidenciaremos mais adiante. Tal posicionamento teórico-metodológico é o mesmo sustentado pelos argumentos de Cavalcanti (2013, p. 224) quando afirma que "quando o conteúdo a ser ensinado na escola está desvinculado da vida em sociedade, do contexto sociocultural e histórico, torna-se árido, desinteressante e tedioso".

Nosso argumento é que a participação colaborativa entre professores da Universidade, acadêmicas dos cursos de Letras, professores do colégio e alunos, comunidade escolar e moradores do bairro possibilita a construção de ações interdisciplinares, fazendo com que, nas práticas de linguagem, os saberes locais possam emergir no espaço escolar.

O artigo está organizado em três seções. Na primeira, apresentamos o "Projeto Memória" e seus participantes, para mostrar a aproximação entre as práticas sociais escolares 
e os saberes locais, proximidade tematizada por abordagens da Linguística Aplicada e viabilizada pela pesquisa etnográfica. Na segunda, abordamos as condições que possibilitaram a proposição do "Projeto Memória" como uma experiência interdisciplinar entre os professores, fundamentada em uma pedagogia culturalmente sensível que extrapola os muros da escola, trazendo também para dentro de seus muros, os moradores do bairro. Na terceira, apresentamos as atividades realizadas e o progressivo envolvimento de professores, alunos, pais e moradores no "Projeto Memória" e, por fim, apresentamos as considerações finais.

\section{Práticas sociais e saberes locais: condições para aprendizagens recíprocas}

O "Projeto Memória", desde o início das atividades no colégio, contou com a participação de 12 professores da Unioeste; 02 professores colaboradores externos; 4 professoras da Equipe de Ensino do Núcleo Regional de Educação; 7 acadêmicas dos cursos de Letras da Unioeste; 25 professores do Colégio Estadual; 2 alunas do Mestrado Interdisciplinar em Sociedade, Cultura e Fronteiras; pais de alunos do Colégio Estadual e moradores do Bairro. Embora o número de participantes diretos não tenha sido tão expressivo, indiretamente o número de beneficiados se expandiu consideravelmente se considerarmos os respectivos alunos dos professores da rede pública, pais e moradores. Do ponto de vista da Universidade, o projeto deu origem a várias produções acadêmicas ${ }^{3}$.

Para criar condições para o desenvolvimento coletivo e participativo dos envolvidos no Projeto Memória, inicialmente organizamos grupos de estudo realizados quinzenalmente, aos sábados - para não interferir no andamento das aulas - com duração de 04 horas. Compuseram esses grupos de estudos: 25 professores e uma supervisora do colégio, sendo 05 professores da rede pública bolsistas; 5 alunas bolsistas e 2 alunas voluntárias dos Cursos de Letras da UNIOESTE; 4 professoras da UNIOESTE. À medida que as atividades foram sendo desenvolvidas e nós, da Universidade, nos tornamos mais próximas, nos sentindo menos intrusas, os alunos, pais e moradores do bairro passaram a integrar paulatinamente as atividades.

\footnotetext{
${ }^{3}$ Dissertação de Mestrado, tese de Doutorado, iniciação científica, pesquisas, estágios supervisionados, grupos de estudo, Projeto Memória, minicursos em leitura, escrita e oralidade, etc.
} 
O bairro em que está situada a escola, de formação relativamente recente, foi criado em 1998 por meio de um programa da prefeitura de Foz do Iguaçu, que realizou o deslocamento de pessoas das áreas de preservação ambiental na região central, para esse local. Por esse motivo, o bairro passou a ser visto por parte dos moradores da cidade de forma estigmatizante - estendida também aos professores da escola - percepção advinda da construção ativa e persistente de um processo de exclusão social, cristalizada em identificações negativas do bairro como um local de atividades ilícitas e perigosas. Essas identificações são inseparáveis das atividades de comércio consideradas ilegais, pois se trata de compra e venda de mercadorias em quantidade e acima da cota permitida, na fronteira entre Ciudad del Este/Paraguai e Foz do Iguaçu/Brasil. Embora as atividades de transporte dessas mercadorias sejam comuns na fronteira, alguns bairros da cidade são estigmatizados como se fossem os únicos a assim procederem. Por esse motivo, os moradores de Foz do Iguaçu em geral buscam manter uma distância social e simbólica em relação ao bairro, impondo a seus moradores uma permanente indignidade pelos princípios dessa diferenciação social entre o legal e o ilegal. Foi essa a motivação que impulsionou a proposição, feita inicialmente pelos professores do colégio, de um "resgate" ${ }^{4}$ da história do bairro, buscando envolver professores, alunos, direção, pais de alunos e membros da comunidade local, justamente com a finalidade de repensar e interferir coletivamente na discriminação e nas desigualdades. Desde a proposição, essa proposta de reconstruir a história do bairro foi designada como "Projeto Memória".

A abordagem teórico-prática que orientou nossa participação no projeto se insere na Linguística Aplicada (MOITA LOPES, 2006, 2013; KLEIMAN; CAVALCANTI, 2007, entre outros), área fundamentalmente centrada no contexto onde as pessoas vivem e agem. Exigindo um constante atravessar de fronteiras, a Linguística Aplicada estabelece interfaces com outros campos de estudo e também com outras áreas de conhecimento. Tal participação colaborativa que identificamos como etnográfica, como aponta Lucena (2015, p. 79), "busca revelar os significados das ações do ponto de vista dos participantes, considerando a relação entre linguagem, contextos específicos e questões sociais e políticas". Também segundo Pires-Santos

\footnotetext{
${ }^{4}$ Essa foi a denominação dada pelos professores da escola para se referir à reconstrução da história de formação do bairro e construção do colégio, realizados pelos professores, alunos e moradores locais, por meio de diferentes atividades.
} 
et al. (2015), a paulatina participação nas atividades do Colégio possibilitou que fôssemos aceitos e assim, pudéssemos construir, conjuntamente, um conhecimento progressivo, sem perder de vista que a etnografia é mais que um método, é a própria teoria vivida (PEIRANO, 1995). Tendo a mesma compreensão a respeito da etnografia, Fritzen e Lucena (2012, p. 56) afirmam que esta "representa um caminho profícuo para gerar compreensão mais detalhada e aprofundada sobre o campo em estudo, uma vez que o desenho metodológico desse tipo de pesquisa é mais flexível e sensível ao contexto social". O registro de todas as atividades desenvolvidas coletivamente foi arquivado em CD. Jornais antigos, fotografias e registro de atividades escritas pelos alunos também foram arquivados, passando a fazer parte do acervo da biblioteca. Para a análise aqui proposta, foram consultados esses arquivos, bem como os diários de campo elaborados pelas professoras/pesquisadoras do colégio e da Unioeste.

\section{Para além dos muros da escola: o Projeto Interdisciplinar Memória}

Uma das queixas frequentes de diretores, professores e supervisores de escolas e, muitas vezes, considerada por estes como causa principal do fracasso escolar, refere-se à quase ausente participação dos pais no processo de educação dos filhos. Se há um empenho dispendioso no sentido de aumentar essa participação, trazendo os pais para a escola, as ações do referido Projeto buscaram fazer o caminho inverso, ou seja, alunos e professores saíram dos muros da escola e foram até o Bairro, objetivando um trabalho com a participação de todos.

No projeto, os professores do colégio definiram como objetivo re(conhecer), do ponto de vista dos alunos e moradores do Bairro, o contexto histórico, cultural e social em que estão inseridos. Eles pretendiam (a) reconstruir, a partir dos relatos dos moradores do Bairro, alunos e pais de alunos, bem como da consulta a documentos arquivados por estes, a história da formação do Bairro e do Colégio, sua conformação na atualidade e seus projetos para o futuro; (b) tecer elos interdisciplinares, para que professores de diferentes áreas do conhecimento pudessem realizar atividades conjuntas complementares, com a finalidade de que os alunos percebessem as inter-relações constitutivas desses conhecimentos; (c) propor práticas de leitura, escrita e oralidade, desenvolvidas conjuntamente pelos professores das diferentes 
disciplinas ${ }^{5}$, levando em conta as funções sociocomunicativas de diferentes gêneros do discurso (Bakhtin, 1992) inseridas no Projeto como prática social inicial: relato, causo, entrevista, poema, literatura de cordel, música, receita culinária, convite, carta-convite, carta de agradecimento, peça de teatro, legenda, autobiografia, biografia, memórias literárias, gráficos e mapas.

A justificativa inicial para a proposição do Projeto Memória, segundo os professores do Colégio Estadual, foi a necessidade de um trabalho interdisciplinar voltado para o reconhecimento das diferenças sociais e culturais dos alunos e moradores do Bairro em relação àquelas privilegiadas pela escola, com a finalidade de contribuir para uma dinâmica do trabalho da comunidade escolar que não desconheça o contexto local. Isto porque o que se evidenciava na comunidade era uma representação negativa da escola e do Bairro, construída pelo olhar dos demais habitantes da cidade que, se representando como "estabelecidos" 6 (ELIAS; SCOTSON, 2000) estigmatizam os moradores daquele Bairro, e até mesmo os professores, depreciados pelos colegas e considerados como "estando em situação de rebaixamento profissional" por trabalharem naquele Colégio. Os alunos e moradores também se auto representavam da mesma forma, como pode ser evidenciado pelos questionamentos de alguns alunos, quando thes foi apresentada a proposta do projeto: "Por que nosso Bairro e não o resgate da história de um Bairro famoso?; Aqui não tem nada de bom!; Nos jornais policiais só se ouve falar de violência no Bairro.; Os ônibus nem querem entrar no Bairro, com medo...; Nós somos discriminados por morar no Bairro.; As pizzarias não fazem entrega no Bairro, pois têm medo! Os professores também se perguntavam: "como sair com essas crianças no horário de aula? É perigoso...".

Outra motivação foi a convicção da exigência de construção de ações interdisciplinares e coletivas, pois, como afirma Savater (1997, p. 38) "ninguém é sujeito na solidão e no isolamento, sempre se é sujeito entre outros sujeitos: o sentido da vida humana não é um

\footnotetext{
${ }^{5}$ Participaram de todas as atividades professores de Língua Portuguesa, Geografia, Ciências, Educação Especial, Matemática, Inglês, Artes e coordenadora pedagógica.

${ }^{6}$ Segundo Elias e Scotson (2000) "estabelecidos" referem-se àqueles que se auto percebem e são percebidos como fazendo parte de um grupo, uma "boa sociedade" (aspas do autor), mais poderosa e melhor, uma identidade social construída a partir de uma combinação singular de tradição, autoridade e influência, fundando o seu poder no fato de se colocarem como um modelo moral para os outros.
} 
monólogo, mas provém do intercâmbio de sentidos, da polifonia coral. Antes de mais nada, a educação é a revelação dos outros, da condição humana como um concerto de cumplicidades inevitáveis".

Entendendo a educação como o empenho mais "humano e humanizador de todos" (SAVATER, 1997, p. 15), mas não perdendo de vista a ressalva do autor quanto aos limites óbvios da tarefa de educar, a educação, em uma perspectiva intercultural crítica, auxiliaria a pensar na interdependência das culturas, promovendo uma educação para a negociação cultural, para o reconhecimento do "EU/Outro", ao promover o diálogo entre os diferentes grupos sociais e culturais, possibilitando o desenvolvimento de capacidades para reexistência em relação aos conflitos culturais e valores diferentes.

A proposta da educação como uma das práticas interculturais, por sua vez, pressupõe alternativas como a proposta de uma pedagogia "culturalmente sensível/relevante" (Erickson (1987); Osborne (1996); Ladson-Billings, (1994); Bortoni-Ricardo e Dettoni (2003). Para os autores, uma pedagogia culturalmente sensível/relevante propiciaria interagir com o aluno e, na convivência entre os referentes culturais dele e nosso, possibilitar o conhecimento, as habilidades e as atitudes. De acordo com Glória Ladson-Billings, em entrevista concedida a Gandin et al. (2002), uma pedagogia culturalmente sensível se ancora em um tripé: a) desempenho escolar: as crianças precisam aprender na escola, mas isto não implica apenas em incutir informações nas crianças, mas em contribuir para que desenvolvam uma análise crítica sobre o que estão aprendendo; b) competência cultural: capacidade de entenderem quem são, de onde vêm e por que estas coisas são importantes para ajudá-las na aprendizagem. A parte central da sua cultura deveria ser a luta pela educação; c) consciência sociopolítica: o que aprendem na escola tem um sentido social mais amplo. A autora nos informa que o vértice sobre a consciência sociopolítica foi proposto com base nas proposições de Paulo Freire.

A partir dessa configuração, a autora afirma que uma consciência sociopolítica ajudaria as crianças a formular e responder às seguintes perguntas: "Por que existem esses padrões de desempenho escolar? Por que crianças que falam uma linguagem diferente parecem nunca ter acesso às classes avançadas de matemática? Por que tantas crianças e adolescentes de cor abandonam a escola?" (GANDIN et al., 2002). Responder a essas perguntas nos ajudou a 
desenvolver ações no sentido de contribuir para que as crianças daquele Colégio enxergassem o quadro social mais amplo, deixando de acreditar que a culpa pelo fracasso é apenas delas.

Tendo a proposta de uma pedagogia interculturalmente sensível/relevante e a formação ampliada do professor como ancoragem, as atividades foram desenvolvidas a partir dos conceitos de linguagem como prática social (FAIRCLOUGH, 2001), não podendo ser vista fora do contexto social em que as práticas discursivas ocorrem sendo, por isso, também consideradas como práticas sociais específicas (GARCEZ, 2001; KLEIMAN, 2007; KOCH; ELIAS, 2007, entre outros), pois são construções sociais e coletivas, tanto na história da coletividade como na história de cada um.

Na concepção de linguagem apontada acima, consideramos que todo enunciado se atualiza em forma de gêneros, isto é, "como tipos relativamente estáveis de enunciados" (BAKHTIN, 1992: 279), o que inclui desde os diálogos cotidianos até as enunciações da vida pública, institucional, artística, científica e filosófica. Os gêneros, para o autor, não são adquiridos em manuais, mas nos processos interativos, surgindo na esfera prosaica da linguagem, por ser esta a esfera mais ampla das formas culturais. É no interior das práticas culturais que outras esferas discursivas são experienciadas.

Com base nos pressupostos apresentados é que foram desenvolvidas todas as atividades do "Projeto Memória", como passamos a apresentar.

\section{Projeto Interdisciplinar Memória e os saberes locais}

Para a reconstrução da história do Bairro e do colégio, os alunos e professores recolheram documentos, artigos de jornais, fotos que registraram diferentes momentos da história do Bairro e da construção do Colégio Estadual junto aos moradores. Esse acervo passou a fazer parte da biblioteca do Colégio. Trouxeram fotos antigas, retratando o terreno vazio, onde posteriormente seriam construídos o colégio e as casas. Fizeram um levantamento dos moradores mais antigos e ainda daqueles que tiveram um papel de liderança quanto às reivindicações por melhorias no Bairro, bem como identificaram os músicos e poetas locais, para serem posteriormente entrevistados. Acompanhados de professores, os alunos percorreram as ruas do Bairro, para registrar, em fotos, o momento atual. Os próprios alunos se surpreenderam com lugares que não conheciam, embora o Bairro seja relativamente 
pequeno e recente. Nesse reconhecimento, encontraram um jornal em funcionamento, uma biblioteca pública organizada e mantida por voluntários do próprio Bairro, várias igrejas, uma biblioteca pública montada e mantida pelos moradores do Bairro, um Grupo de Rap do qual fazem parte alguns alunos da escola e que cedeu documentos digitais de sua autoria.

No levantamento do inventário, como foram designadas as atividades de pesquisa feita, os alunos comentaram a surpresa pelo significativo número de igrejas, evidenciando uma população cristã. Também observaram, na fala das pessoas, a evocação do nome de "Deus" em primeiro lugar. Tais palavras, para os alunos, denotavam fortes sentimentos de fé e esperanças de mudança. Segundo os professores, essas expressões de fé religiosa poderiam ser uma das formas de se distanciarem do estigma do Bairro ligado à criminalidade e, assim, diminuir a ansiedade por serem discriminados, fazendo com que começassem a se sentir parte integrante da construção da própria história.

A cada coleta de dados, os resultados eram partilhados com os demais alunos, professores da escola e com a equipe do Unioeste, usando como recurso a TV pen drive ou multimídia. Nesses momentos, eles identificavam suas casas, as casas dos seus colegas, o comércio, as igrejas, as escolas, Centro Municipal de Educação Infantil (CMEI), o posto de saúde (Postinho), a Pastoral da Criança da igreja católica (local onde muitos estudam ou estudaram catequese), clube esportivo, casinha sobre a árvore de que eles tanto gostavam. Um dos alunos questionou "Como conseguimos fazer tudo ficar tão bonito?" A professora comentou que, provavelmente, eles estavam começando a ver o que não enxergavam porque, talvez, não valorizassem o local onde moravam.

Se no início a maioria dos alunos se mostrava reticente e desmotivada, depois do ruidoso, mas prazeroso "trabalho de pesquisa", cada um procurou se apropriar de sua própria história e, nas pesquisas seguintes, saía na frente, conversando com as pessoas sobre o Projeto, pedindo permissão para fotografar e registrar todos os momentos. As pessoas do Bairro os recebiam com alegria e queriam cooperar. O (re)conhecimento da história como um processo de construção coletiva da memória do Bairro e do colégio foi uma experiência exuberante por ver um trabalho que evidenciou a participação de todos, estreitando ainda mais o relacionamento entre os moradores do Bairro, pais, professores e alunos. 
Dentre os diferentes gêneros discursivos aí desenvolvidos com a participação prática de professores, alunos, e estagiárias dos cursos de Letras Português/Inglês e Português/Espanhol buscou-se um distanciamento de práticas de linguagem escolarizadas que, muitas vezes artificiais, estão desvinculadas das práticas sociais. A escrita e leitura dos diferentes gêneros emergiram em suas funções sociocomunicativas contextuais, alguns deles descritos abaixo.

O gênero discursivo entrevista surgiu da necessidade de os alunos entrevistarem os antigos moradores do Bairro, para conhecerem suas histórias. Para isto, os alunos precisaram, inicialmente, compreender a forma composicional do gênero, sua função sociocomunicativa, o estilo a ser utilizado e a postura ética para a realização de entrevistas.

Antes de realizarem as entrevistas, os alunos leram números antigos do jornal do Bairro que trazia histórias da sua construção. Fizeram também um inventário das lojas comerciais, igrejas, locais de lazer, reciclagem do lixo etc., bem como procuraram saber dos jovens o que faziam em seus momentos de lazer.

Posteriormente, os alunos elaboraram perguntas a serem dirigidas aos moradores, com a finalidade de conhecerem a história narrada por eles. As entrevistas, realizadas pelos alunos e gravadas em vídeo, ocorreram durante um passeio realizado por professores, alunos e demais participantes, em uma Chácara localizada no Bairro, utilizada pelos moradores para momentos de lazer. Todo esse material passou a fazer parte do acervo da biblioteca do Colégio.

Ainda utilizando o gênero entrevista, as professoras de inglês e de matemática realizaram um trabalho interdisciplinar. Com a colaboração dos alunos, organizaram uma pesquisa para obter as seguintes informações junto aos moradores do Bairro: Como é o atendimento à saúde no Bairro? Como está a segurança? Qual o meio de transporte dos moradores? (Carro próprio? Ônibus? Bicicleta?) Qual a renda mensal da família? Quanto tempo mora no Bairro? Qual é o lazer dos moradores? Faz alguma atividade física? Qual?

Após os alunos coletarem todas estas informações, a professora de inglês trabalhou a conversação em inglês, em particular o emprego dos pronomes interrogativos. A professora de matemática utilizou os dados para trabalhar porcentagem e regra de três para chegar a um resultado e, posteriormente, elaborar o gráfico de barras para a confecção dos cartazes com os resultados da pesquisa, os quais foram expostos na Semana Interativa. Desta forma, os alunos envolvidos tiveram a oportunidade de assimilar mais eficazmente os conteúdos exigidos 
na disciplina de matemática. Durante a exposição dos conteúdos os alunos entenderam de uma maneira mais fácil que a porcentagem é uma parte do todo e que a regra de três é importante, ao constatarem a sua utilidade prática.

A escrita dos gêneros discursivos "Carta-convite" e "Carta de agradecimento" foi desenvolvida juntamente com a professora regente de Língua Portuguesa e a estagiária do Curso de Letras da Unioeste. A finalidade desse trabalho foi, após o reconhecimento do gênero, redigir uma carta-convite para ser enviada aos antigos moradores do Bairro que haviam concedido as entrevistas, agradecendo a participação e convidando para que os mesmos comparecessem à apresentação do Projeto Memória, durante a Semana Interativa do Colégio, conforme exemplificado na Figura 1, texto escrito por uma aluna do 6으 ano.

Figura 1 - Texto escrito por uma aluna

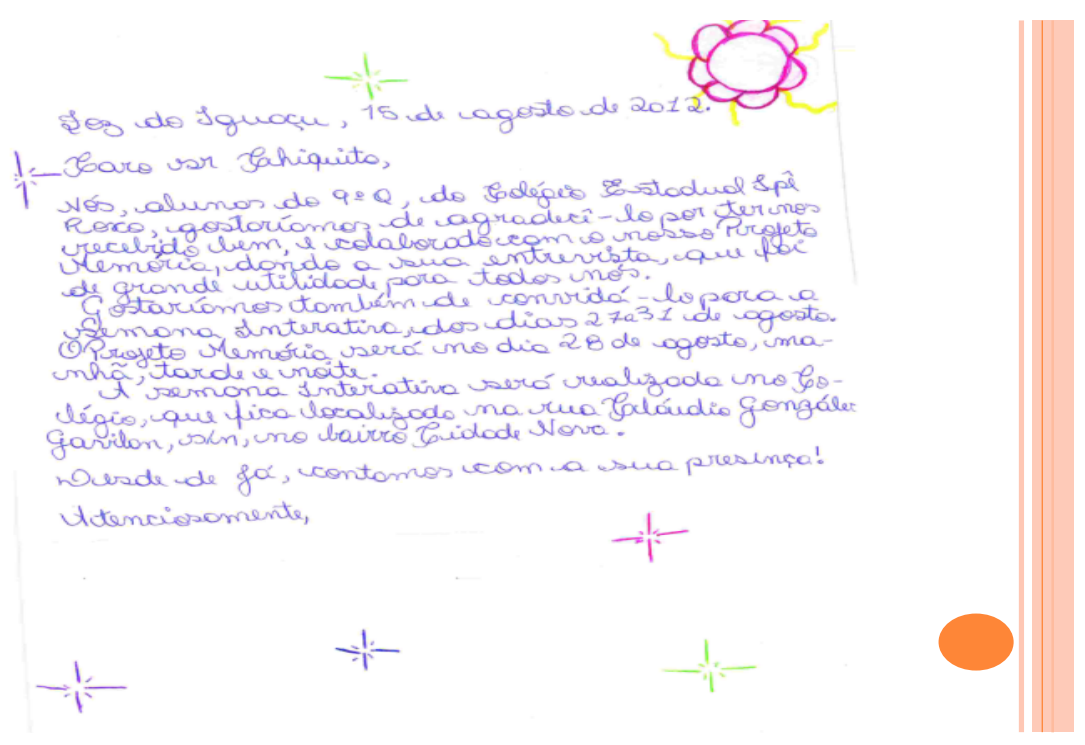

Fonte: acervo da professora da turma.

A escolha do gênero causo foi um meio de incentivar a aproximação entre os jovens e os familiares mais velhos, pois esse gênero praticamente não faz parte, em sua forma composicional original, das interações entre as diferentes gerações. O bairro, embora seja urbano, pela distância e isolamento em relação aos demais Bairro da cidade evidencia-se como tendo uma cultura mais oral. Desta forma, esse gênero contribuiu tanto para a aproximação entre diferentes gerações como também para o conhecimento dos "causos" contados no 
Bairro. Como um gênero oral, raramente trazido para o contexto escolar que, historicamente, tem valorizado em especial a escrita, mostrou-se bastante propício para o trabalho com a variação linguística e para a valorização das variedades menos prestigiadas, contribuindo para a minimização do preconceito linguístico. Depois de os alunos se familiarizarem com o gênero, pesquisaram junto a seus familiares e amigos, os causos conhecidos por eles. Em sala de aula, contaram diversos causos e convidaram um morador para contar um causo muito conhecido no Bairro como "Casa das Mães". Foi um momento de reconhecer e valorizar as histórias contadas pelos seus familiares e amigos.

Os causos contados pelos alunos, por constituírem um gênero oral, foram gravados em áudio e disponibilizados na biblioteca do Colégio. Mas, como alguns alunos não se dispuseram a contar, revelando timidez, alguns causos foram transcritos, mantendo-se a variedade linguística comum à oralidade.

O gênero receita culinária teve como finalidade fazer um levantamento das receitas mais utilizadas nos lares dos alunos. A Receita Culinária aproxima o aluno dos seus familiares, fazendo com que ele conheça os hábitos culinários da sua família, as datas comemorativas em que são feitos pratos especiais e os horários estabelecidos para a alimentação na rotina doméstica. Cada aluno confeccionou um caderno com todas as receitas coletadas, que foi disponibilizado para suas famílias. A professora de Artes auxiliou na confeç̧ão dos cadernos de receita.

Esse trabalho foi coordenado pela professora de português, uma estagiária do curso de Letras da Unioeste e a professora de matemática. Entre as receitas, aquela que se mostrou mais apreciada e elaborada em suas casas foi o bolo de chocolate. Então, essa receita foi escolhida como a "Especialidade da Casa" do Bairro. Professores e alunos fizeram o bolo na cozinha do colégio, agindo com responsabilidade e cuidado naquele ambiente. No momento da degustação, a professora de matemática trabalhou com as medidas (massa, volume, temperatura) e frações. Um dos momentos mais especiais foi quando o bolo estava pronto para a degustação, o que nos fez compreender que as crianças aprendem efetivamente a partir de seus próprios interesses.

O desenvolvimento dos gêneros discursivos biografia e autobiografia - conforme exemplificado na Figura 2, escrito por uma aluna do 7ㅇ ano - possibilitou respectivamente o 
conhecimento e o registro da história de vida de antigos moradores do Bairro e também levou à reflexão feita pelos alunos, sobre suas próprias vidas, ligando passado, presente e projetando para o futuro, como vidas importantes que estão construindo uma história e fazendo parte de culturas plurais. $O$ interessante é que, quando Ihes foi apresentada a atividade, imediatamente muitos levantaram a questão de que quem merece biografia ou autobiografia são as pessoas importantes. Portanto, essa atividade abriu possibilidades para a autovalorização tanto dos moradores do Bairro como dos alunos, que passaram a se ver como importantes construtores da história e da cultura.

Figura 2 - Texto escrito por um aluno

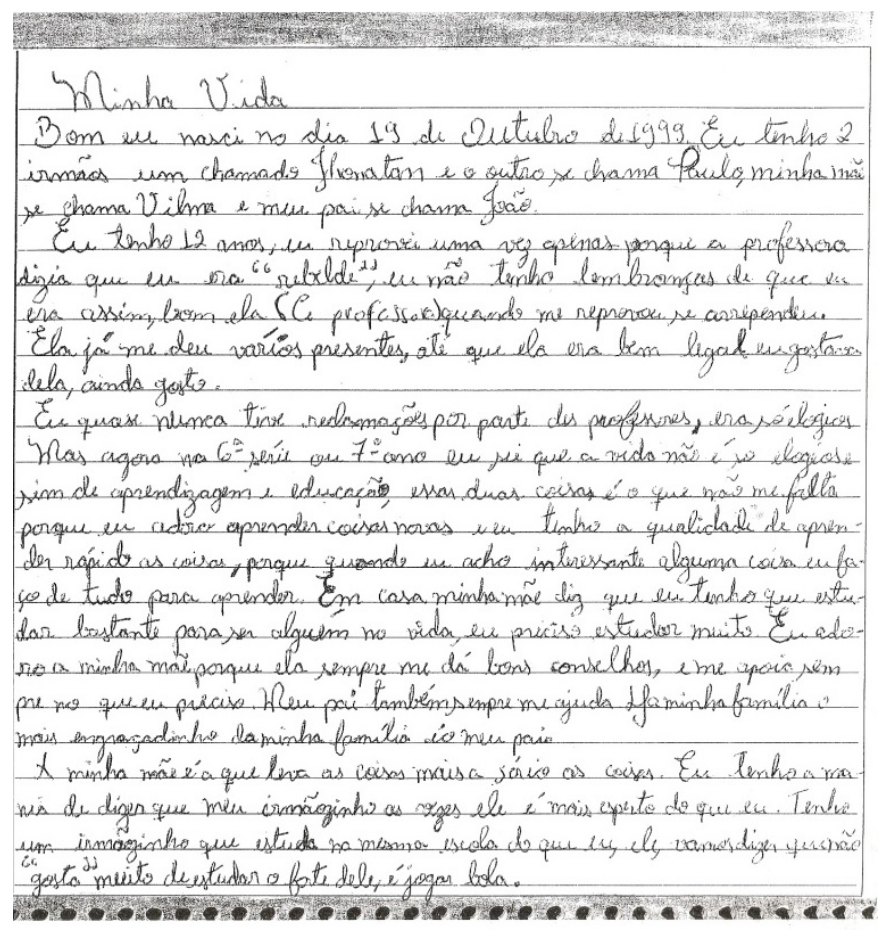

Fonte: acervo da professora da turma.

A professora encarregada de desenvolver com os alunos dos primeiros anos do Ensino Médio, o Gênero Teatro, sentiu que precisava de um texto dramático que contasse a história do bairro, uma história da qual também faz parte há 11 anos. História especial, que precisava ser relembrada com cuidado, amor e carinho, segundo suas palavras, "história de gente sofrida que, em busca de um sonho, seguiu trilhando uma trajetória e que não pensa em parar de 
lutar". Essa história precisava ser registrada e encenada com e para os alunos e aos moradores, a fim de que pudessem relembrar e entender o passado e projetar o futuro.

A atividade se iniciou com o documentário sobre a Comunidade da Maré. Conforme relato da professora, "assistimos, discutimos e fizemos algumas relações com o bairro. Muitos falaram de suas dificuldades e da falta de lazer. Os mais antigos ainda relataram suas experiências desde o início do bairro, por onde caminham desde sua fundação".

A atividade resultou em um resumo produzido pelos alunos a respeito do documentário, para posterior escrita da peça de teatro. Além deste documentário, professora e alunos assistiram a um outro sobre as Cataratas do Iguaçu, que destacava os moradores mais antigos da cidade de Foz do Iguaçu. Essa atividade resultou numa discussão a respeito das pessoas mais velhas, da sua importância e experiência. Para que entendêssemos um pouco mais do Bairro, precisávamos de alguns relatos das pessoas mais velhas, dos mais antigos moradores. Então, foram feitas algumas entrevistas com os moradores, gravadas e registradas pelos alunos. Eles fizeram vídeos das entrevistas e depois estes vídeos foram apresentados à própria comunidade.

O estudo não parou por aí. Além de alguns documentários, de entrevistas, buscamos documentos oficiais do município de Foz do Iguaçu. Pesquisamos alguns documentos da Companhia Habitacional de Foz do Iguaçu (COHAFOZ) e notícias do Jornal Gazeta do Iguaçu, parte do acervo pessoal de um antigo morador do Bairro. Todos os relatos orais e escritos recolhidos na pesquisa de campo foram reunidos e o texto para a peça de teatro começou a ser escrito pela professora e pelos alunos.

A elaboração da peça teve também a colaboração de uma estagiária do Curso de Letras da Unioeste, que fez um estudo mais aprofundado das técnicas utilizadas para a encenação de uma peça. Além disso, ajudou na montagem do texto e nos ensaios. À medida que trabalhavam com a parte técnica, os alunos foram ficando mais à vontade, compreenderam bem os elementos necessários para a encenação de uma peça de teatro.

Como o tempo para a encenação da peça era muito curto porque a Semana Interativa se aproximava, a professora procurou adiantar a escrita, fora do horário de aula. Quando apresentou aos alunos o esboço que havia feito, estes levantaram os seguintes questionamentos: "Professora, os moradores daqui não falam assim não, eles não tiveram escolaridade; nós, os filhos, que estamos estudando, é que usamos mais concordâncias e uma 
linguagem mais formal; logo, temos que representar a voz do povo do Bairro e essa voz do texto não pertence a eles".

Ouvindo-os, o texto foi modificado várias vezes, o que rendeu muitas reescritas e discussões que resultaram na apresentação da peça, encenada nos três turnos - matutino, vespertino e noturno - na Semana Interativa da Comunidade Escolar realizada uma vez por ano no Colégio.

Não podemos deixar de mencionar que todos os envolvidos no Projeto Memória observaram uma significativa mudança de todos os participantes, para além da preocupação com os resultados das avaliações institucionais.

O poema abaixo compõe a peça encenada e sintetiza a Memória do Bairro e do Colégio que foi interesse do projeto.

\author{
Em cada consciência, uma lembrança. \\ O Bairro, um sonho, uma esperança, uma nova chance... \\ A hora não é de sofrer, não deixa a tristeza saber. \\ A vida ensina, a escola da vida foi assim. \\ Sonhos não envelhecem. \\ Homens que aqui ocuparam se resumiam em sonhos. \\ O sonho da casa própria! \\ Um passo atrás do outro, um tijolo que se erguia, uma mão amiga \\ Uma gente querida, numa nova vila, vida, paisagem. \\ Cidade Nova, memória viva hoje e sempre! (Patrícia de Souza)
}

\title{
Considerações Finais
}

A participação colaborativa entre professores da Universidade, acadêmicas dos cursos de Letras, professores do colégio e alunos, comunidade escolar e moradores do Bairro possibilitou a construção de ações interdisciplinares, fazendo com que, nas práticas de linguagem, emergissem os saberes locais no espaço escolar. O diálogo entre os diferentes grupos sociais e culturais possibilitou aprofundar formas de reconhecimento social dos alunos como moradores imersos na sócio-história de ocupação do espaço urbano, bem como contribui para o desenvolvimento de capacidades para (re)existência em relação ao distanciamento 
simbólico e social imposto pelos moradores da cidade de Foz do Iguaçu e, ao mesmo tempo, fazendo com que se percebessem inseridos no contexto do qual fazem parte.

Do ponto de vista da formação inicial e contínua de professores, foi possível ressignificar uma formação ampliada para atuar nesse contexto sociolinguisticamente complexo de fronteira, marcado por desigualdades sociais e por diferentes práticas de linguagem.

Mas, o mais importante foi a certeza de que não é possível um retrocesso, pois houve uma mudança significativa para todos. Como afirmaram todos os participantes, o "Projeto Memória" não encerrou, tendo sua continuidade com o trabalho coletivo e além dos muros da escola. Ao desestabilizar algumas certezas, surgiram alternativas para tecer um eterno devir, um constante deslocamento dos resultados da educação no sentido que todos nós almejamos em nosso país. O trabalho coletivo de todos e além dos muros da escola permanece, aprofundando o sentido da educação como uma "revelação dos outros e da condição humana como um concerto de cumplicidades inevitáveis" (SAVATER, 1997).

\section{Referências}

BAKHTIN, M. Estética da criação verbal. São Paulo: Martins Fontes, 1992.

BLOMMAERT, J.; RAMPTON, B. Language and superdiversity. Diversities, v. 13, n. 2, 2011.

BORTONI-RICARDO, S. M.; DETTONI, R. V. Diversidades lingüísticas e desigualdades sociais: aplicando a pedagogia culturalmente sensível. In: COX, M.I; ASSIS-PETERSON, A. (Ed.). Cenas de sala de aula. Campinas: Mercado de Letras, 2003. p. 81-104.

CAVALCANTI, M. C. Educação linguística na formação de professores de línguas: intercompreensão e práticas translíngues. In: MOITA LOPES, L.P. (Org.) Linguística Aplicada na modernidade tardia. São Paulo: Parábola, 2013. p. 211-226.

ELIAS, N.; SCOTSON, J. L. Os estabelecidos e os outsiders: sociologia das relações de poder a partir de uma pequena comunidade. Rio de Janeiro: Jorge Zahar Editor, 2000.

ERICKSON, F. Transformation and School Success: The politics and culture of educational achievement. Anthropology \& Education Quartely, p. 335-356, 1987. https://doi.org/10.1525/aeq.1987.18.4.04x0023w

FAIRCLOUGH, N. Discurso e mudança social. Brasília: UnB, 2001.

FRITZEN, M. E. P.; LUCENA, M. I. P. O olhar da etnografia em contextos educacionais Interpretando práticas de linguagem. Blumenau: Edifurb, 2012.

GANDIN, L. A.; DINIZ-PEREIRA, J. E.; HYPOLITO, Á. M. Para além de uma educação multicultural: teoria racial crítica, pedagogia culturalmente relevante e formação docente (entrevista com a 
professora Gloria Ladson-Billings). Educação e Sociedade, ano XXIII, n. 79, p. 275-293, ago. 2002. https://doi.org/10.1590/S0101-73302002000300014

GARCEZ, L. H. C. Técnicas de redação: o que é preciso saber para bem escrever. São Paulo: Martins fontes, 2001.

KLEIMAN, A. B; MORAES, S.E. Leitura e interdisciplinaridade. Campinas: Mercado de Letras, 2007.

KLEIMAN, B. K.; CAVALCANTI, M. C. (Org.). Linguística Aplicada: suas faces e interfaces. Campinas: Mercado de Letras, 2007.

KOCH, I. V.; ELIAS, V. M. Ler e compreender: os sentidos do texto. São Paulo: Contexto, 2007.

LADSON-BILLINGS, G. The dreamkeepers: Successful teachers for African-American children. San Francisco: Jossey-Bass, 1994.

LUCENA, M. I. P. Práticas de linguagem na realidade da sala de aula: contribuições da pesquisa de cunho etnográfico em Linguística Aplicada. D.E.L.T.A., v. 31 especial, 2015, p. 1-34. https://doi.org/10.1590/0102-445093806057590158

MOITA LOPES, L. P. (Org.). Linguística Aplicada na modernidade recente. São Paulo: Parábola, 2013.

MOITA LOPES, L. P. (Org.). Por uma Linguística Aplicada indisciplinar. São Paulo: Parábola, 2006.

OSBORNE, A. Practice into theory into practice: culturally relevant pedagogy for students we have marginalized and normalized. Anthropology \& Education Quartely, v. 27, n. 3, p. 285-314, 1996. https://doi.org/10.1525/aeq.1996.27.3.04x0351m

PEIRANO, M. A favor da etnografia. Rio de Janeiro: Relume Dumara, 1995.

PIRES-SANTOS, M. E.; LUNARDELLI, M. G.; JUNG, N. M.; SILVA, R. C. M. "Vendo o que não se enxergava": condições epistemológicas para construção de conhecimento coletivo e reflexivo da língua(gem) em contexto escolar. D.E.L.T.A., n. 31 especial, p. 1-34, 2015. https://doi.org/10.1590/0102-4450761813738654418

SAVATER, F. O valor de educar. São Paulo: Planeta, 1997.

VERTOVEC, S. Super-diversity and its implications. Ethnic and Racial Studies, v. 30, n. 6, p. 10241054, nov. 2007. https://doi.org/10.1080/01419870701599465 